\title{
HIGH-VOLTAGE-GAIN INTEGRATED BOOST-SEPIC DC-DC CONVERTER FOR RENEWABLE ENERGY APPLICATIONS
}

\author{
Bruno G. de Assis, Eduardo P. C. Braga, Claudinor B. Nascimento, Eloi Agostini Júnior \\ Universidade Tecnológica Federal do Paraná - UTFPR, Campus Ponta Grossa, Ponta Grossa - PR, Brasil \\ e-mail: elaric_10@outlook.com, eduardopcbraga@gmail.com, claudinor@utfpr.edu.br, eloiagostini@utfpr.edu.br
}

\begin{abstract}
This paper presents the analysis of a nonisolated high-voltage-gain single-switch dc-dc converter based on the integration of the boost and SEPIC topologies. The converter employs a voltage multiplier at the output of the SEPIC stage, which is connected in series with the output of the boost stage, aiming a high step-up ratio operation with limited duty cycle values. An accurate steady state analysis considering the influence of the leakage inductance of the SEPIC coupled inductor in the energy transfer process is detailed in the paper. The several theoretical results are then used to derive a design methodology for the circuit. Experimental results for a $500 \mathrm{~W}, 48 \mathrm{~V}$ input voltage, $400 \mathrm{~V}$ output voltage, $96.3 \%$ peak efficiency and $100 \mathrm{kHz}$ switching frequency prototype are provided to demonstrate the feasibility of the proposed scheme and to validate the mathematical analysis carried out.
\end{abstract}

Keywords - High voltage gain, Integrated boostSEPIC, Renewable energy systems, Snubberless converter.

\section{INTRODUCTION}

According to the U.S. EIA (Energy Information Administration), the worldwide energy consumption will be increased by approximately $30 \%$ until 2040 . Non-renewable sources, such as natural gas, coal and oil, are responsible for $70 \%$ of the overall energy production. In addition to the concern with energy scarcity due to the limited availability of the sources, fossil resources are also known to have the negative impact of polluting the environment and thus contributing for global warming [1]. Although fossil resources remain as the predominant energy sources in the present, it is expected that the energy production from renewable sources increases at the average rate of $2.3 \%$ per year until 2040 [1]. In this sense, it is crucial that the electronic systems used for energy processing exhibit an increased efficiency and reduced cost.

Concerning renewable sources, such as fuel cell and photovoltaic, systems processing power levels in the order of hundreds of Watts are usual and energy is made available at low voltage levels. Therefore, dc-dc converters operating with high voltage gain become a necessity. In this sense, it is known that the conventional boost converter would be the straightforward choice for non-isolated applications, but its efficiency tends to be drastically reduced as the voltage gain

Manuscript received 21/03/2019; first revision 25/04/2019; accepted for publication $06 / 07 / 2019$, by recommendation of Editor Marcello Mezaroba. http://dx.doi.org/10.18618/REP.2019.3.0025 is increased [2]-[4]. In order to overcome this issue, numerous solutions have been proposed in the literature [2] [27]. As addressed in [2]-[4], most of them are based on the boost converter using a two-winding coupled inductor for achieving a high step-up ratio with limited duty cycle values. However, some problems related to the blocking voltage on the semiconductors and high input current ripple can reduce the overall system performance and increase the component count. According to [3], the key characteristics of a high step-up dc-dc converter for renewable energy applications are: (a) high efficiency; (b) low component count; (c) reduced cost and size; and (d) low-ripple input current. Aiming to meet the most these characteristics, high-voltage gain dc-dc converters based on the SEPIC have been proposed, as can be seen in [5]-[14]. The circuits proposed in [7],[10],[12]-[14] employ coupled inductor and voltage multiplier cells to obtain high-voltage gain, while in [5],[8],[9],[11] only coupled inductor is used. Other examples of high step-up dc-dc converters based on the conventional boost or SEPIC converters can be found in [15]-[25]. In [16], the boost-flyback converter is proposed, which requires a dissipative circuit to clamp the voltage on the output diode and also a high number of turns ratio to achieve high voltage gain. The boost-based circuits introduced in [17]-[19] also employ voltage multiplier cells, while the topologies presented in [20]-[25] use more than one active switch to perform interleaved operation ([20][22]) and soft switching on the devices ([23]-[25]). In [26], a high efficiency two-switch buck-based solution exhibiting a linear voltage gain and with soft-switching capability was proposed. Another two-switch topology was introduced in [27], based on the conventional boost-flyback converter.

In the circuit presented in this work, which has been previously studied in [7] employing a quasi-resonant strategy, the blocking voltage of all semiconductors is naturally clamped, thus not requiring the addition of auxiliary snubber or clamping circuits in a practical implementation.

A detailed qualitative and quantitative description of the circuit operation is provided in this paper, along with a stepby-step design procedure and experimental verification of the key theoretical results. Finally, the analysis is validated through experimental tests performed with a $500 \mathrm{~W}$ prototype operating at a switching frequency of $100 \mathrm{kHz}$.

\section{HIGH-VOLTAGE-GAIN BOOST-SEPIC DC-DC CONVERTER}

The power stage of the high step-up boost-SEPIC dc-dc converter using a voltage multiplier cell (IBS-VM), firstly introduced in [7] under a quasi-resonant operation, is shown 


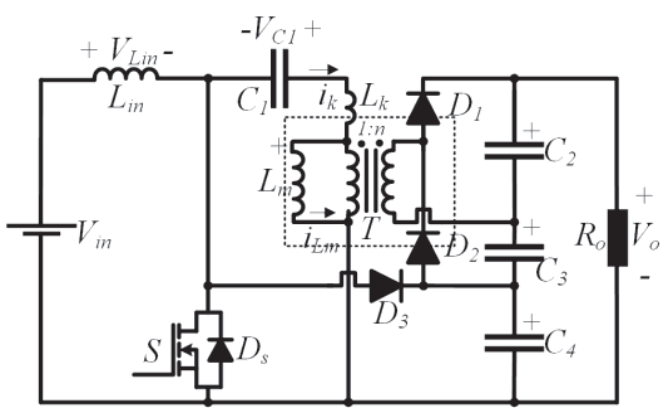

Fig. 1. High-voltage-gain dc-dc converter based on the integration of the boost and SEPIC topologies employing a voltage multiplier cell [7].

in Figure 1. The circuit is the result of the integration between the boost and SEPIC topologies, in which the shared elements are the input inductor $L_{i n}$ and the switch $S$. The elements $C_{1}, C_{2}, C_{3}, C_{4}, T, D_{1}$ and $D_{2}$ compose the remaining SEPIC stage, while $D_{3}$ completes the boost segment.

In addition to increasing the voltage gain, this configuration prevents voltage ringing to occur on diodes $D_{1}$ and $D_{2}$, since their blocking voltages are clamped by capacitors $C_{2}$ and $C_{3}$. Hence, no additional snubber or clamping circuit must be included in the system to limit the voltage spikes on these components. It is also noteworthy that using the voltage multiplier configuration completely changes the operating principle of the coupled inductor $T$, given that the average value of its magnetizing current must be null at steady state. Consequently, the coupled inductor operates as a conventional transformer and do not require gap to prevent core saturation.

\section{OPERATING PRINCIPLE AT STEADY STATE}

In order to perform the analyses performed in this paper, two simplifying assumptions are made:

1) The voltages on $C_{1}, C_{2}, C_{3}$ and $C_{4}$ and the current through $L_{i n}$ are considered ripple free (treated as constants);

2) All semiconductors are treated as ideal elements.

The qualitative analysis of the IBS-VM converter reveals the existence of five distinct operating stages within a switching cycle in the continuous conduction mode (CCM), as depicted in Figure 2. The CCM operation in the IBS-VM converter is defined on $i_{\text {Lin }}$, which never becomes null during the switching period. A brief explanation on each operating stage is given as follows:

First stage $\left(\mathbf{t}_{\mathbf{0}}-\mathbf{t}_{1}\right)$ [cf., Figure 2.a]: starts when the switch $S$ is turned on at $\mathrm{t}=\mathrm{t}_{0}$. The input voltage source transfers energy to $L_{i n}$ and the inductance $L_{k}$ is discharged. Energy is also being transferred to the output capacitor $C_{2}$. As soon as $L_{k}$ is completely discharged, this stage ends.

Second stage $\left(\mathbf{t}_{1}-\mathbf{t}_{2}\right)$ [cf., Figure 2.b]: as soon as $i_{k}$ has its direction reversed, at the beginning of the second stage, diode $D_{1}$ blocks and $D_{2}$ becomes forward biased. In this stage, energy is still transferred to $L_{i n}$. Regarding the output stage, only $C_{3}$ receives energy. At $\mathrm{t}=\mathrm{t}_{2}$, the switch $S$ is turned-off, thus finishing this stage.

Third stage (t $\left.\mathbf{t}_{2}-\mathbf{t}_{3}\right)$ [cf., Figure 2.c]: the blocking of $S$ makes diode $D_{3}$ to become forward biased. This stage is of great importance in the converter operation, since it prevents the leakage inductance of the transformer to generate a voltage spike on the switch by providing a current path towards the output capacitor $C_{4}$. This stage is completed when $i_{k}$ becomes positive.

Fourth stage $\left(\mathbf{t}_{3}-\mathbf{t}_{4}\right)$ [cf., Figure 2.d]: at $\mathrm{t}=\mathrm{t}_{3}, i_{k}$ becomes positive, implying that $D_{1}$ and $D_{2}$ become forward and reverse biased, respectively. During this stage, energy is transferred to the output capacitors $C_{2}$ and $C_{4}$. At $\mathrm{t}=\mathrm{t}_{4}, D_{3}$ blocks since $i_{k}$ becomes equivalent to $i_{i n}$, thus finishing the fourth stage.

Fifth stage ( $\mathbf{t}_{4}-\mathbf{t}_{\mathbf{5}}$ ) [cf., Figure 2.e]: during fifth and last operating stage, the current through $L_{k}$ is maintained equal to $I_{i n}$. The only output capacitor receiving energy is $C_{2}$. As soon as the switch $S$ is turned on, this stage ends and the switching cycle is over.

Based on the description of the five steady-state operating
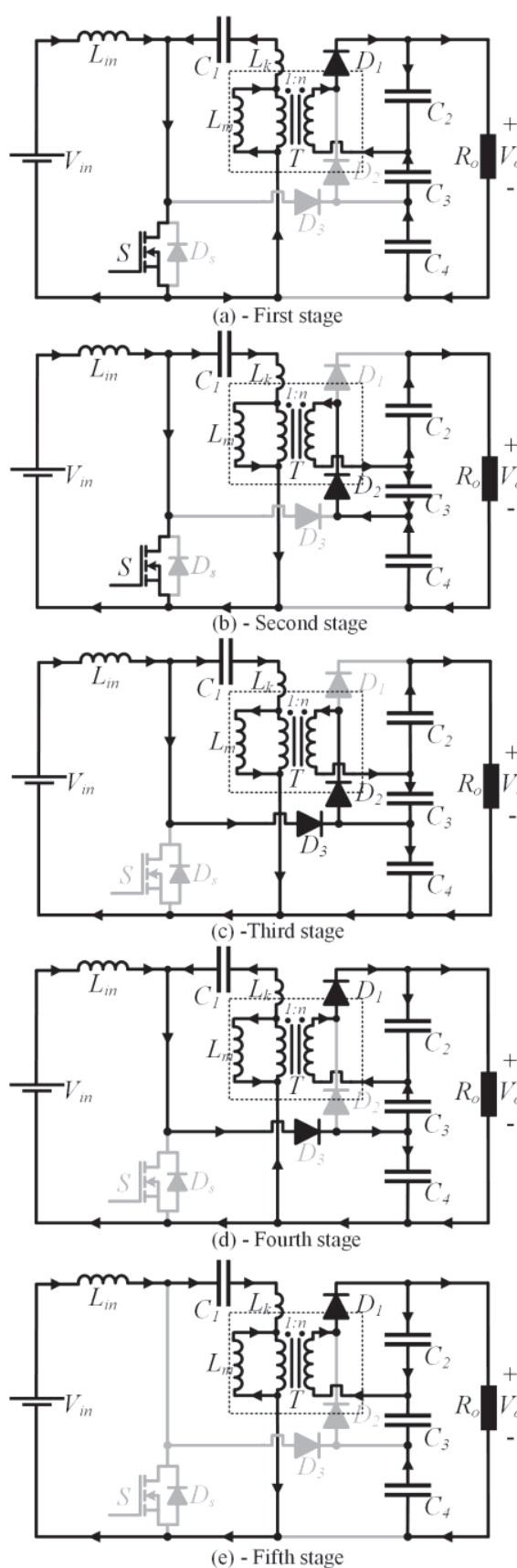

Fig. 2. Operating stages of the high-voltage-gain dc-dc boostSEPIC converter in CCM. 


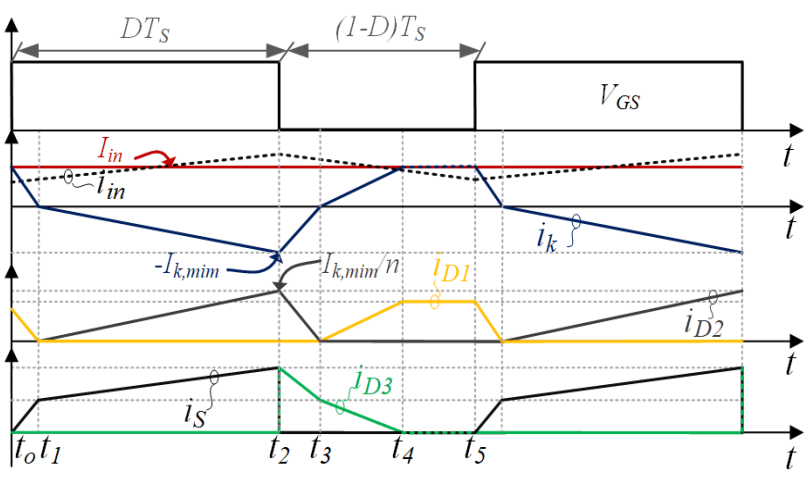

Fig. 3. Theoretical waveforms at steady state of $i_{i n}, i_{k}, i_{D 1}, i_{D 2}, i_{D 3}$ and $i_{S}$.

stages of the converter, whose equivalent circuits are presented in Figure 2, one can derive the voltage/current waveforms on every element of the circuit. The key waveforms regarding the operation of the IBS-VM converter at steady state are given in Figure 3.

\section{MATHEMATICAL ANALYSIS AT STEADY STATE}

In this section, an accurate mathematical analysis considering the influence of the leakage inductance $L_{k}$ in the energy transfer process is performed for the converter using the proposed non-resonant scheme. This accurate analysis provides the means to quantify the influence of $L_{k}$ on the static gain and to demonstrate that $D_{1}, D_{2}$ and $D_{3}$ turn off with ZCS. Some initial definitions are made as follows:

$$
\begin{aligned}
& \Delta t_{k}=t_{k}-t_{k-1} ; f_{s}=\frac{1}{T_{s}} ; \alpha=\frac{f_{s} L_{k}}{R_{o}} ; \\
& M=\frac{V_{o}}{V_{\text {in }}} ; q_{2}=\frac{V_{C 2}}{V_{\text {in }}} ; q_{3}=\frac{V_{C 3}}{V_{\text {in }}} ; q_{4}=\frac{V_{C 4}}{V_{\text {in }}} .
\end{aligned}
$$

Where: $\Delta t_{k}$ corresponds to the duration of the kth operating stage; $T_{s}$ and $f_{s}$ refer to the switching period and switching frequency, respectively; $\alpha$ is a factor involving the switching frequency, the leakage inductance $L_{k}$ and the output resistance $R_{o} ; M$ is the static gain and $q_{2}, q_{3}$ and $q_{4}$ are the partial static gains.

On analyzing the five operating stages, one can determine the set of equations

$$
\begin{gathered}
I_{i n}-\frac{\left(n V_{i n}+V_{C 2}\right)}{n L_{k}} \Delta t_{1}=0, \\
I_{k, \text { min }}-\frac{\left(n V_{i n}-V_{C 3}\right)}{n L_{k}} \Delta t_{2}=0, \\
I_{k, \text { min }}-\frac{\left(n V_{C 4}-n V_{i n}+V_{C 3}\right)}{n L_{k}} \Delta t_{3}=0,
\end{gathered}
$$

and

$$
I_{\text {in }}-\frac{\left(n V_{C 4}-n V_{i n}-V_{C 2}\right)}{n L_{k}} \Delta t_{4}=0
$$

that must hold whenever the converter operates at steady state, where $n$ corresponds to the primary to secondary number of turns ratio of the transformer. The parameters $I_{i n}$ and $I_{k, \min }$ are unknown current levels indicated in Figure 3 to be determined at the end of the analysis. Similarly, the partial output voltages $V_{C 2}, V_{C 3}$ and $V_{C 4}$ are unknowns to be found in order to completely quantify the steady-state energy transfer behavior of the IBS-VM converter.

The output voltage can be varied by means of duty cycle adjustment in the pulse-width-modulation (PWM) applied to the switch $S$. From the key waveforms depicted in Figure 3, it is possible to verify that

$$
\Delta t_{1}+\Delta t_{2}=\frac{D}{f_{s}}
$$

and

$$
\Delta t_{3}+\Delta t_{4}+\Delta t_{5}=\frac{(1-D)}{f_{s}}
$$

relate the durations of the five operating stages of the IBSVM converter with the duty cycle set in the PWM

The last set of equations necessary to solve the problem is obtained from the Volt-second balance on the magnetizing inductance $L_{m}$ and the Ampère-second balance on the output capacitors $C_{2}, C_{3}$ and $C_{4}$, as given by

$$
\begin{gathered}
V_{C 2}\left(\Delta t_{1}+\Delta t_{4}+\Delta t_{5}\right)-V_{C 3}\left(\Delta t_{2}+\Delta t_{3}\right)=0 \\
n I_{\text {in }}\left(2 \Delta t_{3}+\Delta t_{4}\right)+n I_{k, \text { min }} \Delta t_{3}+ \\
-I_{\text {in }}\left(\Delta t_{1}+\Delta t_{4}+2 \Delta t_{5}\right)=0
\end{gathered}
$$

and

$$
\begin{aligned}
& n I_{\text {in }}\left(2 \cdot \Delta t_{3}+\Delta t_{4}\right)+ \\
& +n I_{k, \text { min }} \Delta t_{3}-I_{k, \text { min }}\left(\Delta t_{2}+\Delta t_{3}\right)=0 .
\end{aligned}
$$

It is noteworthy that applying the Ampère-second balance on $C_{1}$ would be redundant, since the resulting equation is a linear combination of (9) and (10). Also, the voltage across $C_{l}$ can be calculated prior to this analysis, observing that

$$
V_{C 1}=V_{\text {in }}
$$

in order to guarantee that the average value of the voltages on $L_{i n}, L_{k}$ and $L_{m}$ are all null in steady state.

Finally, in general, it is interesting to have the results in terms of the output voltage, which is

$$
V_{o}=V_{C 2}+V_{C 3}+V_{C 4}
$$

in this converter, given that the output capacitors are associated in series.

On solving the system formed by the set of equations (2)(10) and (12), the values of $I_{i n}, I_{k, \min }, V_{C 2}, V_{C 3}, V_{C 4}, \Delta t_{1}, \Delta t_{2}$, $\Delta t_{3}, \Delta t_{4}$ and $\Delta t_{5}$ can be calculated and a complete mathematical description of the converter is achieved. However, given the extension of the solution, the results are not provided in this paper, but with the aid of a computer software one could easily solve the equations for any set of parameters.

Finally, the average value of the output current is given by

$$
I_{o}=\frac{V_{o}}{R_{o}}=\frac{f_{s}\left[I_{i n}\left(2 \Delta t_{3}+\Delta t_{4}\right)+I_{k, \min } \Delta t_{3}\right]}{2} .
$$

At this point, it is important to mention that further analyses, such as voltage/current stresses, conduction losses, switching losses, small-signal dynamic modeling and even an optimization of the converter would require these results to be carried out. However, they are not performed in this paper for the reason of being beyond the scope of this research.

\section{A. Input Current Ripple}


The choice of $L_{\text {in }}$ has a direct impact on the input current ripple, as given by

$$
\Delta I_{\text {Lin }}=\frac{D V_{\text {in }}}{f_{s} L_{\text {in }}} .
$$

Therefore, it is possible to determine the value of $L_{\text {in }}$ such that input current ripple is limited to some desired value, which is an important theoretical result for the adequate design of the converter.

\section{B. Voltage Ripples on $C_{1}, C_{2}, C_{3}$ and $C_{4}$}

In this section, the voltage ripples on the capacitors contained in the power stage of IBS-VM converter are derived. These results are fundamental to determine the capacitance values that keep the voltage ripples limited to maximum specified values. It is noteworthy that the voltage ripples on $C_{2}, C_{3}$ and $C_{4}$ depend on the load characteristics, which is here considered purely resistive. However, based on the content of this paper, the reader can easily derive these ripples for other kinds of load.

The voltage ripple on $C_{1}$ is computed based on the current waveform depicted in Figure 4. The highlighted area is the region correspondent to the discharge of $C_{l}$. Thus, the voltage ripple $\Delta V_{C l}$ can be determined by

$$
\Delta V_{C 1}=-\int_{t_{1}}^{t_{3}} d v_{C 1}=-\frac{1}{C_{1}} \int_{t_{1}}^{t_{3}} i_{C 1} d t=-\frac{\left(A_{1}+A_{2}\right)}{C_{1}} .
$$

Computing the values of the areas $A_{1}$ and $A_{2}$ and substituting the values of $I_{k, \text { min }}, \Delta t_{2}$ and $\Delta t_{3}$ into (15) yields

$$
\Delta V_{C 1 \%}=\frac{\Delta V_{C 1}}{V_{\text {in }}}=\frac{q_{2}^{2}\left(n-q_{3}\right)\left[n\left(q_{4}-1\right)+q_{3}\right]}{2 n^{2} f_{s}^{2} L_{k} C_{1} q_{4}\left(q_{2}+q_{3}\right)^{2}},
$$

which provides the voltage ripple on $C_{1}$ as a percentage of the input voltage $V_{\text {in }}$ and in terms of the definitions established in (1).

By proceeding in a similar way, the voltage ripples on $C_{2}$, $C_{3}$ and $C_{4}$ can be computed. Figure 4 also presents the waveforms of the currents through $C_{2}, C_{3}$ and $C_{4}$, highlighting the charging regions of these capacitors. The analysis of these waveforms results in the percent voltage ripples given by

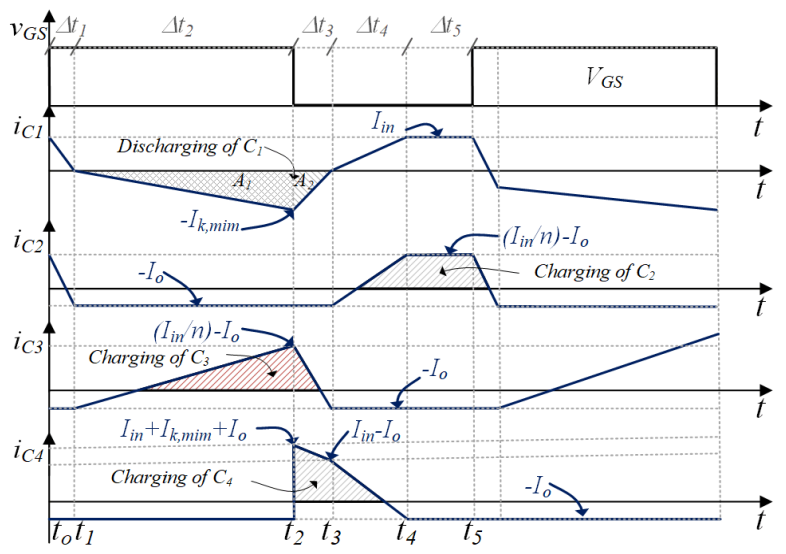

Fig. 4. Theoretical waveforms at steady state of $i_{C l}, i_{C 2}, i_{C 3}$ and $i_{C 4}$.

$$
\begin{gathered}
\Delta V_{C 2 \%}=\frac{\Delta V_{C 2}}{V_{C 2}}=\frac{n\left(\frac{I_{\text {in }}}{n}-I_{o}\right)^{2}\left(\Delta t_{1}+\Delta t_{4}\right)}{2 C_{2} I_{\text {in }} V_{C 2}}+ \\
+\frac{2 I_{\text {in }}\left(\frac{I_{\text {in }}}{n}-I_{o}\right) \Delta t_{5}}{2 C_{2} I_{\text {in }} V_{C 2}}, \\
\Delta V_{C 3 \%}=\frac{\Delta V_{C 3}}{V_{C 3}}=\frac{n\left(\frac{I_{k, \text { min }}}{n}-I_{o}\right)^{2}\left(\Delta t_{2}+\Delta t_{3}\right)}{2 C_{3} I_{k, \min } V_{C 3}}
\end{gathered}
$$

and

$$
\begin{aligned}
\Delta V_{C 4 \%}=\frac{\Delta V_{C 4}}{V_{C 4}}= & \frac{\left(1+D-q_{4}-\frac{f_{s} L_{k} I_{o}}{2 V_{\text {in }}}\right) n I_{o}}{f_{s} C_{4} q_{4}\left[\left(1-q_{4}\right) n+q_{2}\right] V_{i n}}+ \\
& +\frac{D q_{2} I_{o}}{f_{s} C_{4} q_{4}\left[\left(1-q_{4}\right) n+q_{2}\right] V_{\text {in }}},
\end{aligned}
$$

where: $I_{o}$ corresponds to the constant output current drained by the output resistance $R_{o}$.

The results (17) and (18) could also be written in terms of the definitions established in (1). However, due to the extension of the resulting equations, they are provided in terms of the auxiliary parameters used in the mathematical analysis.

\section{Static Gain}

On solving the set of equations (2)-(10) and (12), it is possible do demonstrate that the ideal static gain (considering $\alpha \rightarrow 0$ ) of the IBS-VM converter is given by

$$
M^{\text {ideal }}=\frac{1+n}{1-D} \text {. }
$$

There is no closed-form solution for the static gain of the IBS-VM converter considering nonzero values for $L_{k}$. However, with the aid of a computer program, the set of equations provided in the mathematical analysis can be solved and the static gain can be evaluated for any operating condition.

In order to demonstrate how $L_{k}$ affects the static gain, some graphs are provided next. It is noteworthy that the load characteristic and switching frequency have influence on the static gain whenever $L_{k} \neq 0$. It means that $M$ is also dependent on the values of $R_{o}$ and $f_{s}$, and consequently on $\alpha$,

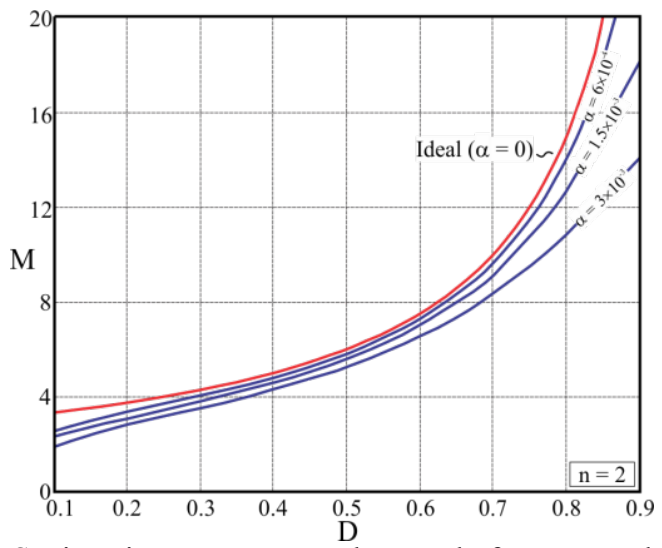

Fig. 5. Static gain curves versus duty cycle for some values of $\alpha$ considering $n=2$. 
in addition to $D$ and $n$. Figure 5 shows static gain curves for some values of $\alpha$ considering $n=2$, which is drawn from the numerical solution of the system formed by the set of equations (2)-(10) and (12).

\section{ZCS on Diodes $D_{1}, D_{2}$ and $D_{3}$}

The existence of the inductance $L_{k}$ in the circuit allows limiting the derivatives of the current through the coupled inductor. Consequently, the slew rates of the currents on $D_{l}$ and $D_{2}$ are also limited. It means that if $L_{k}$ is high enough, ZCS is achieved on these diodes. In order to verify the switching conditions on $D_{1}$ and $D_{2}$, the slew rate of the current through these elements must be computed prior to their blocking. The blocking of $D_{1}$ and $D_{2}$ occurs at the end of the first and third stages, respectively. The slew rate (SR) of their current prior to the blocking event is given by

$$
S R_{D 1}=-\frac{\left(n V_{i n}+V_{C 2}\right)}{n^{2} L_{k}}
$$

and

$$
S R_{D 2}=-\frac{\left(n V_{C 4}-n V_{i n}+V_{C 3}\right)}{n^{2} L_{k}},
$$

respectively.

The same reasoning applies to $D_{3}$, the current of which decreases with a slew rate of

$$
S R_{D 3}=-\frac{\left(n V_{C 4}-n V_{i n}-V_{C 2}\right)}{n L_{k}}
$$

before it turns off at the end of the fourth stage.

The results (21)-(23) allow the designer to verify whether the switching losses of $D_{1}, D_{2}$ and $D_{3}$ are as low as desired. If these losses must be further reduced, a small external inductor can be added to the circuit to lower the slew rate of the currents through the diodes. Alternatively, the coupled inductor could have its construction oriented to increasing $L_{k}$, thus not requiring the addition of another element to the circuit.

\section{E. Blocking Voltages on the Semiconductors}

One of the key advantages of the IBS-VM converter is that the blocking voltages of its semiconductors are lower than the output voltage $V_{o}$. Specifically, the maximum voltages on $S, D_{1}, D_{2}$ and $D_{3}$ are given by

$$
V_{S \max }=V_{D 3 \max }=V_{C 4}
$$

and

$$
V_{D 1 \text { max }}=V_{D 2 \max }=V_{C 2}+V_{C 3} \text {. }
$$

Equations (24) and (25) are fundamental to choose adequate devices when designing the IBS-VM converter.

\section{F. Performance Comparison with Other Topologies}

To finish the theoretical analysis of the IBS-VM converter, a comparative performance with other converters based on the SEPIC topology is presented in the Table I. The chosen initial criteria for comparison are the existence of a single switch and low-ripple input current performed by all circuits. The converters of [10] and [11] have the same components count, voltage gains and voltage stress on the main switch of the IBS-VM converter, but the sum of the voltage stress on the diodes of [11] is higher. Comparing only with [10], the sum of the energy stored in the four capacitors is lower in the IBS-VM converter, and thus the proposed solution potentially requires a lower volume of capacitive elements. Regarding the circuits proposed in [12] and [13], they employ more components than the IBS circuit studied in this work, however their voltage gains are higher. Both circuits present lower voltages stress on the main switch, while the sum of the voltages on the diodes of [12] and [13] is similar and higher than that verified in the IBSVM converter, respectively.

\section{STEP-BY-STEP DESIGN METHODOLOGY}

In this section, a step-by-step design procedure for the high step-up integrated boost-SEPIC converter based on the mathematical analysis performed in section IV is detailed. This is done by gathering the main results derived in section IV and then proposing sequential steps to determine the values of the converter's parameters that meet a set of design specifications. The suggested steps are as follows:

1) Specify the desired distribution of the output voltage $V_{o}$ between the partials $V_{C 2}, V_{C 3}$ and $V_{C 4}$ in accordance with (12);

2) Find $I_{i n}, I_{k, \text { min }}, \Delta t_{1}, \Delta t_{2}, \Delta t_{3}, \Delta t_{4}$ and $\Delta t_{5}$ in terms of $D, n$ and $L_{k}$ using the set of equations (2)-(8);

3) Solve numerically the system of equations (9), (10) and (13) and determine the values of $D, n$ and $L_{k}$ that satisfy the

\begin{tabular}{|c|c|c|c|c|c|c|}
\hline \multirow{2}{*}{$\begin{array}{l}\text { Boost-SEPIC } \\
\text { Based Circuit }\end{array}$} & \multirow{2}{*}{$\begin{array}{l}\text { Ideal Voltage } \\
\text { Gain }\left(V_{o} / V_{i n}\right)\end{array}$} & \multirow{2}{*}{$\begin{array}{l}\text { Voltage Stress on } \\
\text { the Main Switch }\end{array}$} & \multirow[t]{2}{*}{$\Sigma V_{\text {diodes }}$} & \multirow{2}{*}{$\begin{array}{l}\text { No. of } \\
\text { Diodes }\end{array}$} & \multicolumn{2}{|c|}{$\begin{array}{l}\text { No. of Passive } \\
\text { Components }\end{array}$} \\
\hline & & & & & Inductor & Capacitor \\
\hline in [10] & $\frac{1+n}{1-D}$ & $\frac{M}{1+n} V_{\text {in }}$ & $\frac{(1+2 n) M}{1+n} V_{i n}$ & 3 & $\begin{array}{l}1 \text { single } \\
1 \text { coupled }\end{array}$ & 4 \\
\hline in [12] & $\frac{2+n+D}{1-D}$ & $\frac{M+1}{3+n} V_{i n}$ & $\frac{(3+2 n)(M+1)}{3+n} V_{i n}$ & 4 & $\begin{array}{l}1 \text { single } \\
1 \text { coupled }\end{array}$ & 5 \\
\hline in [13] & $\frac{2+n+D(1-n)}{1-D}$ & $\frac{M+n+1}{1+2 n} V_{i n}$ & $\frac{(5+3 n)(M+n+1)}{1+2 n} V_{i n}$ & 4 & $\begin{array}{l}1 \text { single } \\
1 \text { coupled }\end{array}$ & 5 \\
\hline
\end{tabular}
design specifications;

4) Calculate the value of $L_{\text {in }}$ using (14);

TABLE I

Comparison with Other SEPIC Based Single-Switch Converters 
5) Compute the values of $C_{1}, C_{2}, C_{3}$ and $C_{4}$ using (16), (17), (18) and (19), respectively;

6) Determine the RMS values of voltages and currents on the primary and secondary windings of the coupled inductor $T$. The voltages can be determined from the analysis of the equivalent circuits provided in Figure 2 and the current stresses can be computed from the waveform of $i_{k}$ depicted in Figure 3 . These values are necessary to the physical design of this magnetic element;

7) Calculate the voltage and current stresses on the semiconductors using the several results obtained from the theoretical analysis (the equations regarding the stresses have not been included in section IV due to their extension).

\section{EXPERIMENTAL RESULTS}

Aiming to validate the theoretical analysis carried out, a

TABLE II

Design Specifications for the 500 W Prototype of the IBSVM Converter

\begin{tabular}{cc}
\hline Parameter & Value \\
\hline$P_{\text {out }}$ & $500 \mathrm{~W}$ \\
\hline$V_{\text {in }}$ & $48 \mathrm{~V}$ \\
\hline$V_{o}$ & $400 \mathrm{~V}$ \\
\hline$V_{C 2}$ & $150 \mathrm{~V}(151 \mathrm{~V})^{*}$ \\
\hline$V_{C 3}$ & $150 \mathrm{~V}(137 \mathrm{~V})^{*}$ \\
\hline$V_{C 4}$ & $100 \mathrm{~V}(112 \mathrm{~V})^{*}$ \\
\hline$f_{s}$ & $100 \mathrm{kHz}$ \\
\hline$\Delta I_{L i n \%}$ & $20 \%$ \\
\hline$\Delta V_{C 1 \%}$ & $10 \%$ \\
\hline$\Delta V_{C 2 \%}$ & $2 \%$ \\
\hline$\Delta V_{C 3 \%}$ & $2 \%$ \\
\hline$\Delta V_{C 4 \%}$ & $2 \%$ \\
\hline$\Delta V_{o}$ & $1 \%$ \\
\hline
\end{tabular}

*Values considering the inclusion of an external inductance of $1 \mu \mathrm{H}$ to increase $L_{k}$.

TABLE III

Parameters Values for the $500 \mathrm{~W}$ Prototype of the IBSVM Converter

\begin{tabular}{cc}
\hline Parameter & Value \\
\hline$M$ & 8.333 \\
\hline$q_{2}$ & 3.146 \\
\hline$q_{3}$ & 2.854 \\
\hline$q_{4}$ & 2.333 \\
\hline$n$ & 3.25 \\
\hline$D$ & 0.518 \\
\hline$L_{\text {in }}$ & $113 \mu \mathrm{H}, \mathrm{APH} 40 \mathrm{P} 60$ \\
\hline$L_{k}$ & $2.3 \mu \mathrm{H}$ (leakage of the primary winding of $\mathrm{T}+$ an \\
\hline$T$ & external inductance of $1 \mu \mathrm{H})$ \\
\hline$C_{1}$ & ETD39, 3C95, 8/26 turns, Litz 38AWG, $L_{m}=301 \mu \mathrm{H}$ \\
\hline$C_{2}, C_{3}$ & $9.4 \mu \mathrm{F}(2 \times 4.7 \mu \mathrm{F}$ in parallel $)$ \\
\hline$C_{4}$ & $2.2 \mu \mathrm{F}$ \\
\hline$D_{1}, D_{2}$ & $\mathrm{STTH} 20 \mathrm{R} 04$ \\
\hline$D_{3}$ & MBR40250TG \\
\hline$S$ & IRFP4668PBF \\
\hline
\end{tabular}
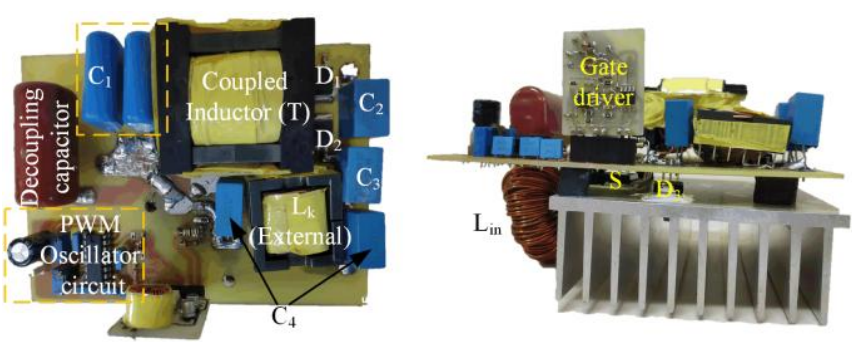

Fig. 6. Picture of the $500 \mathrm{~W}$ IBS-VM prototype built to perform the
$500 \mathrm{~W}$ prototype of the IBS-VM converter with the specifications listed in Table II was built and tested in laboratory. The design procedure discussed in the previous section was used to determine the parameters values shown in Table III. It is noteworthy that including an external inductance to increase the value of $L_{k}$ lead to a slight modification on the distribution of the output voltage between $V_{C 2}, V_{C 3}$ and $V_{C 4}$, as highlighted in Table II. Figure 6 exhibits a picture of the IBS-VM converter prototype built for the experimental tests.

Key experimental waveforms were taken at the nominal operating condition to validate the theoretical analysis performed in this paper. Output voltage and current and input voltage and current waveforms are depicted in Figure 7.a, in which an input current ripple of $24 \%$ is verified. The output voltage $V_{o}$ and its respective partials $\left(V_{C 2}, V_{C 3}\right.$ and $\left.V_{C 4}\right)$ are shown in Figure 7.b. Measurements indicate $154.4 \mathrm{~V}, 136.6$ $\mathrm{V}$ and $110 \mathrm{~V}$ for $V_{C 2}, V_{C 3}$ and $V_{C 4}$, respectively, which are close to their specified values. As can be seen in Figure 7.c, a duty cycle value of 0.558 was necessary to ensure the operation with a constant output voltage value of $400 \mathrm{~V}$,
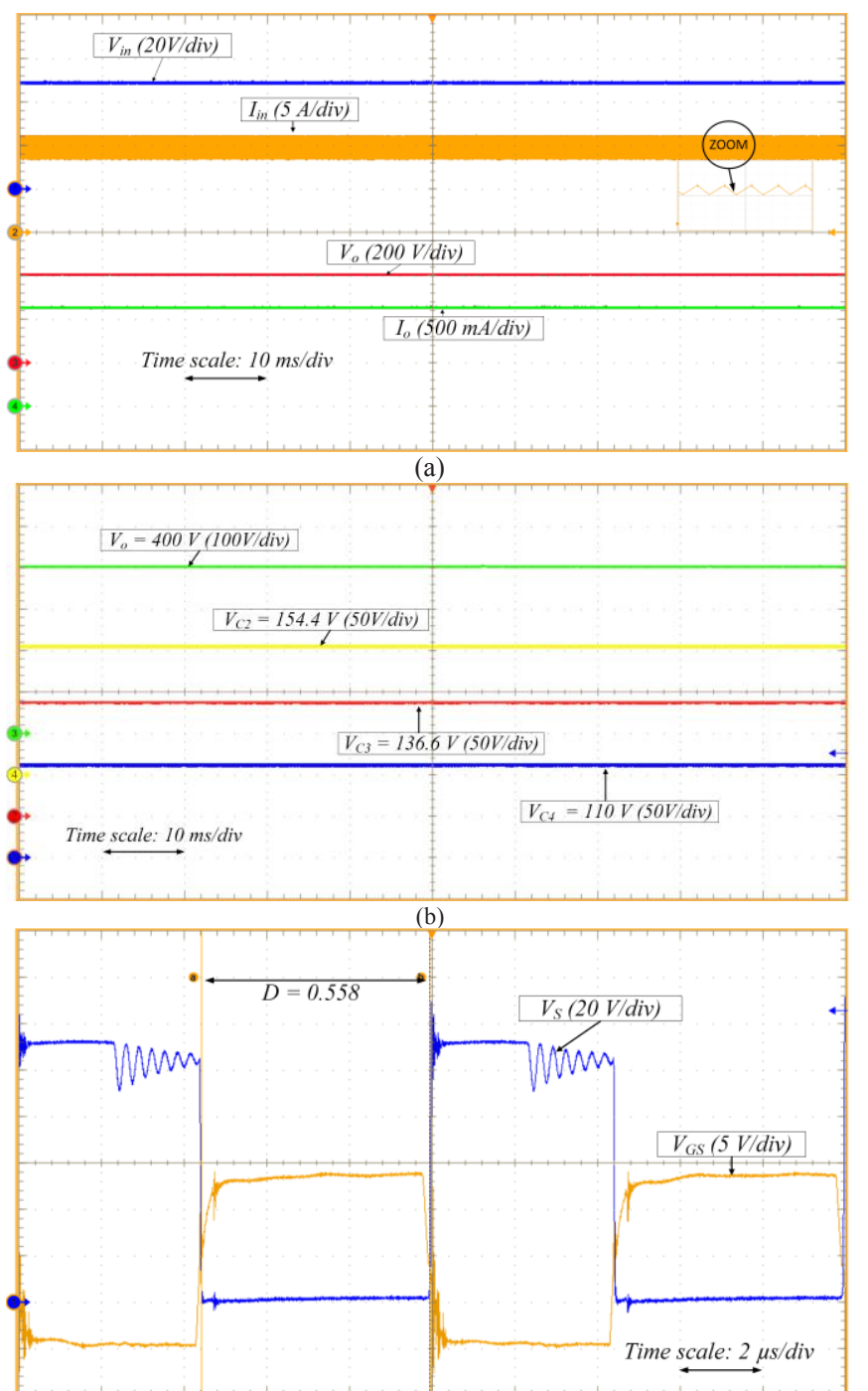

(c)

Fig. 7. Key experimental results at $P_{\text {out }}=500 \mathrm{~W}$ : (a) Input voltage $V_{\text {in }}$, input current $i_{i n}$, output voltage $V_{o}$ and output current $I_{o}$; (b) output voltage $V_{o}$ and partial output voltages $V_{C 2}, V_{C 3}$ and $V_{C 4}$; (c) drain-to-source voltage $V_{S}$ and gate-to-source voltage $V_{G S}$ on $S$. 
being this value higher than the 0.518 predicted in the theoretical analysis. This difference is due to the losses on the components that have been disregarded in the
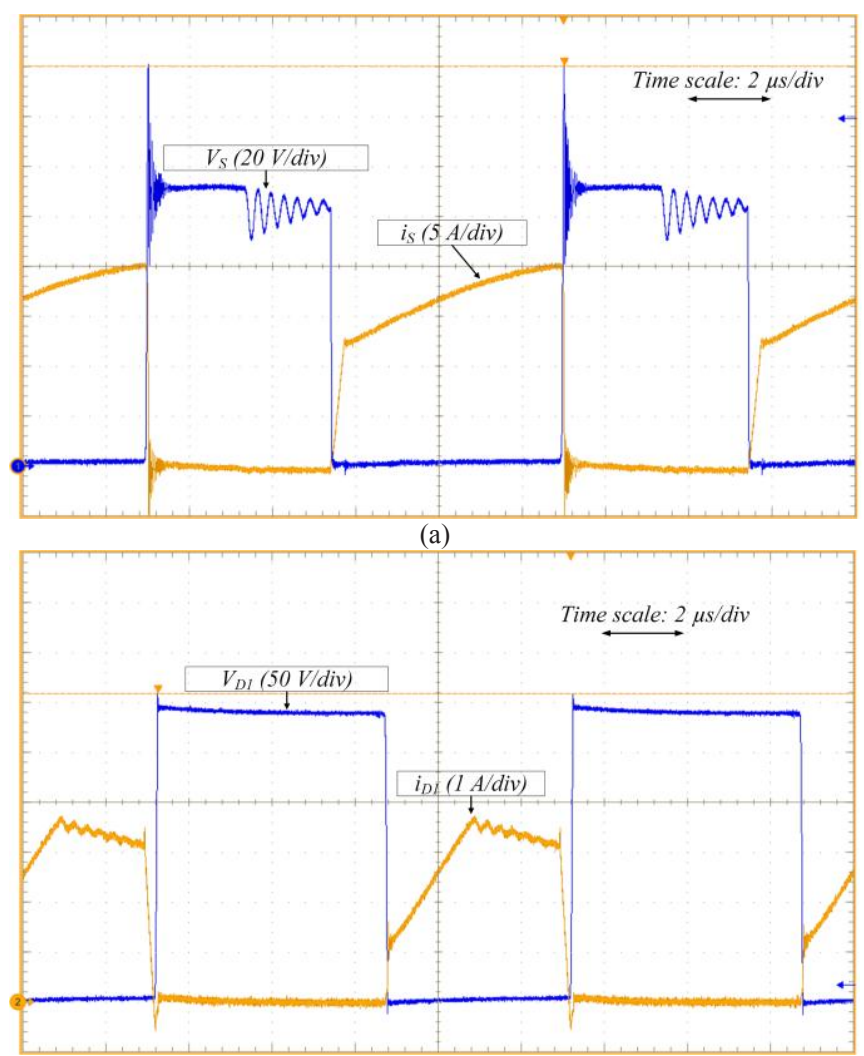

(b)

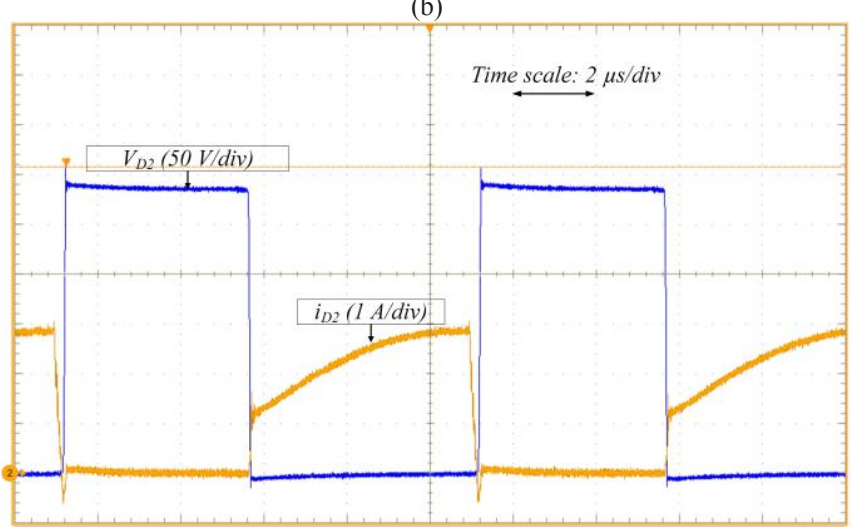

(c)

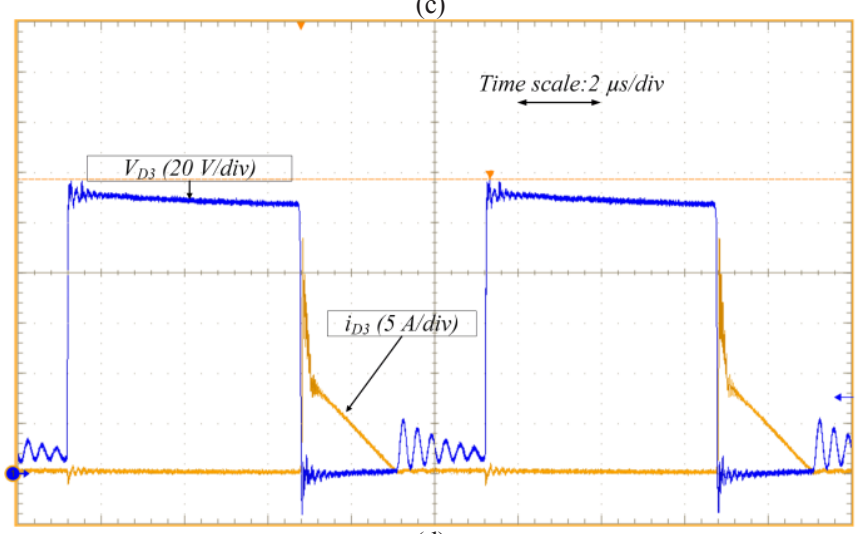

(d)

Fig. 8. Main experimental results of the semiconductor devices at $P_{\text {out }}=500 \mathrm{~W}$ : (a) $V_{S}$ and $i_{S}$; (b) $V_{D 1}$ and $i_{D 1}$; (c) $V_{D 2}$ and $i_{D 2}$ and (d) $V_{D 3}$ and $i_{D 3}$ mathematical analysis. The blocking voltages $V_{S}, V_{D 1}, V_{D 2}$ and $V_{D 3}$ and the currents $i_{S}, i_{D 1}, i_{D 2}$ and $i_{D 3}$ are shown in Figure 8.a to Figure 8.c. A higher voltage spike in $V_{S}$ is observed on Figure 8.a than in Figure 7.c, since a wire loop was inserted in the prototype to acquire the waveform of $i_{S}$. The measurements indicate $S R_{D 1}=-17.65 \mathrm{~A} / \mu \mathrm{s}, S R_{D 2}=$ $-16.67 \mathrm{~A} / \mu \mathrm{s}$ and $S R_{D 3}=-5.1 \mathrm{~A} / \mu \mathrm{s}$, while the theoretical predictions are $-12.64 \mathrm{~A} / \mu \mathrm{s},-14.20 \mathrm{~A} / \mu \mathrm{s}$ and $-7.6 \mathrm{~A} / \mu \mathrm{s}$, respectively. The difference observed can be justified by the voltage ripple on $C_{1}$ and on the parasitic elements that have been disregarded during the analysis. However, the theoretical predictions are sufficiently accurate to serve as the basis to guarantee ZCS on $D_{1}, D_{2}$ and $D_{3}$ during the design of the IBS-VM converter. Well behaved waveforms were verified for $V_{D 1}$ and $V_{D 2}$ without adding any auxiliary clamping circuit to the converter, being this a key difference between the proposed solution and the conventional integrated boost-SEPIC converter presented in [5]. It is important to observe that the blocking voltage of every semiconductor has a lower value than the output voltage (400 $\mathrm{V})$.

Figure 9.a presents the voltage on $C_{1}$ along with the input voltage, proving the validity of (11). It also verified that the ripple on $V_{C l}$ is in accordance with the design specifications. The waveform of the current through $L_{k}$ is depicted in Figure 9.b. Some resonance is observed in this waveform caused by the existence of a nonzero voltage ripple on $C_{l}$, which has been disregarded in the theoretical analysis. However, this resonance plays a minor role in the energy transfer process, given the good agreement between the measurements and the design specifications.

Finally, efficiency measurements for several values of

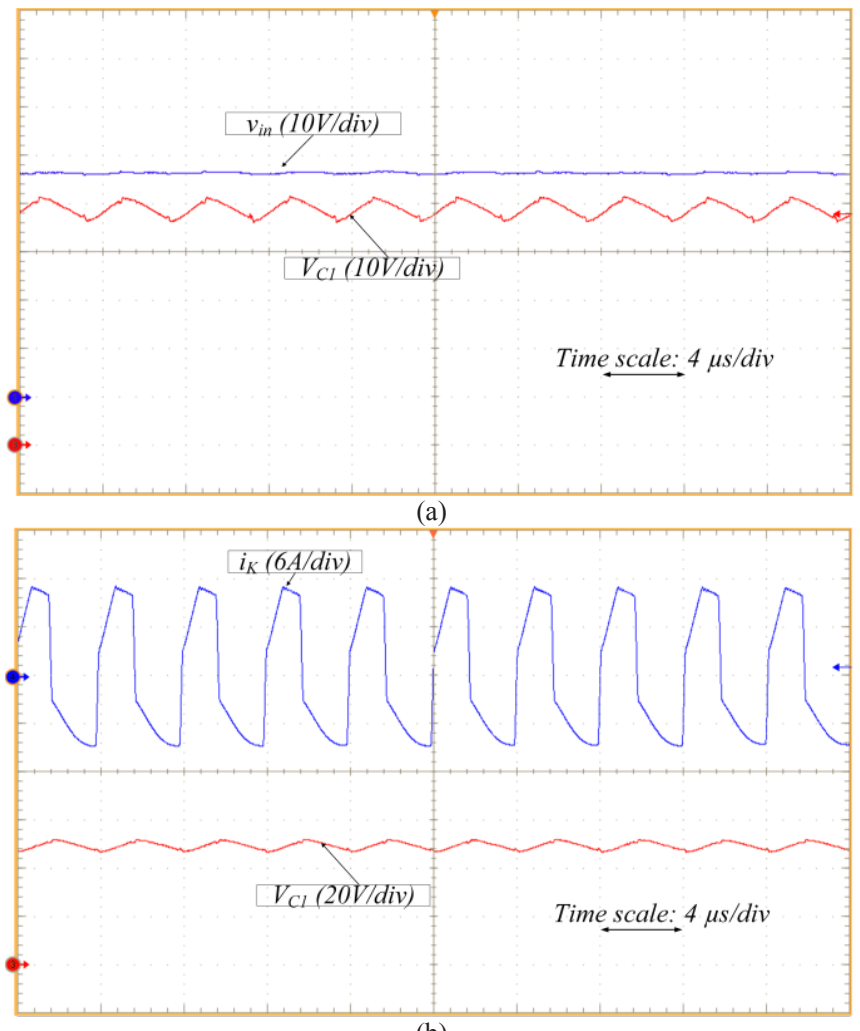

(b)

Fig. 9. Key experimental results at $P_{\text {out }}=500 \mathrm{~W}$ : (a) $V_{C l}[10 \mathrm{~V} / \mathrm{div}]$ and $V_{\text {in }}[10 \mathrm{~V} / \mathrm{div}]$ and (b) $i_{k}[6 \mathrm{~A} / \mathrm{div}]$ and $V_{C l}[20 \mathrm{~V} / \mathrm{div}]$. 


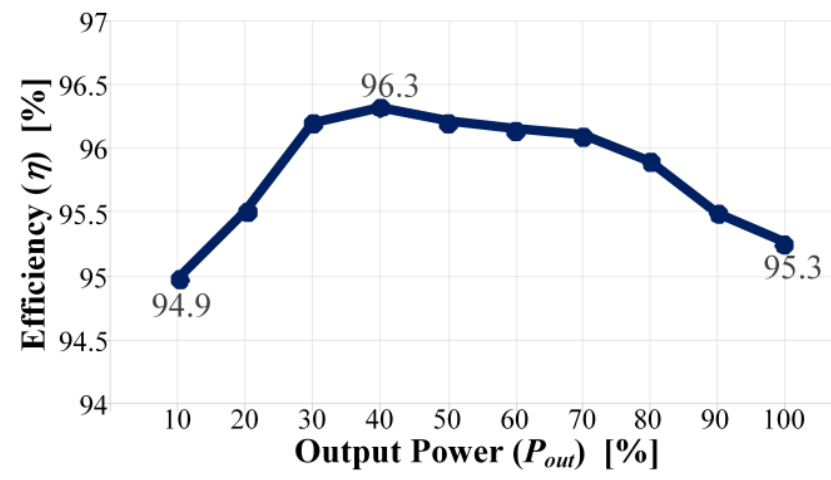

Fig. 10. Efficiency measurements vs. output power at $V_{o}=400 \mathrm{~V}$.

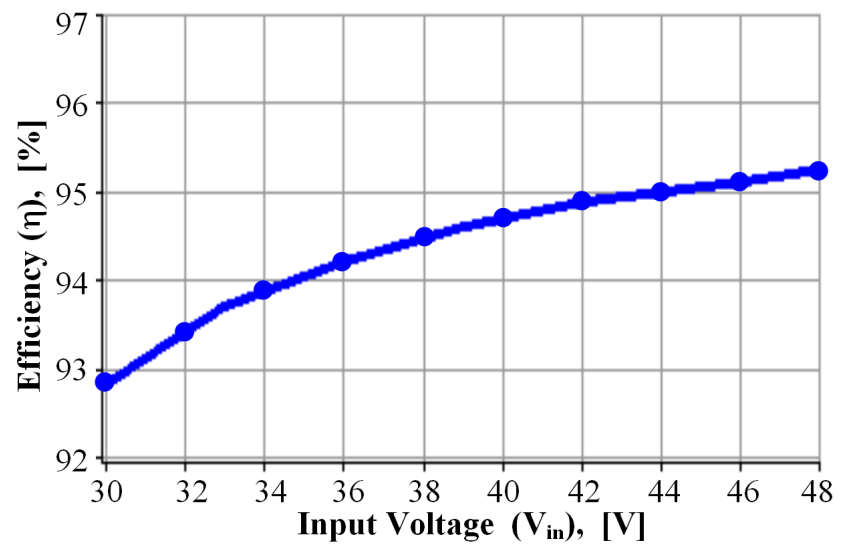

Fig. 11. Efficiency measurements under input voltage variations at $P_{\text {out }}=500 \mathrm{~W}$

output power are shown in Figure 10. The measurements were performed maintaining the output voltage fixed at 400 V. A maximum efficiency of $96.3 \%$ was observed at $40 \%$ of the rated output power. At nominal conditions, the converter exhibited an efficiency level of $95.3 \%$. It is noteworthy that the efficiency is above $94.9 \%$ for the entire range of 10 $100 \%$ of output power. In order to verify the performance of the IBS-VM converter under input voltage variations, efficiency measurements were taken considering an input voltage range of $30-48 \mathrm{~V}$ and $P_{\text {out }}=500 \mathrm{~W}$, as depicted in Figure 11. As expected, an efficiency drop is verified as the input voltage is decreased due to higher current stresses. The efficiency values were obtained using the precision power analyzer Yokogawa WT500 and the waveforms depicted in Figures 7, 8 and 9 were acquired with the digital oscilloscope Tektronix DPO 7254.

\section{CONCLUSION}

In this paper, the operation of a snubberless high-voltagegain dc-dc converter based on the integrated boost-SEPIC was investigated. Differently from the conventional IBS converter reported in [5], the use of a voltage multiplier cell at the output of the SEPIC stage enables the circuit to operate with a higher voltage gain and also prevents the coupled inductor to have a dc level on its magnetizing current. Moreover, the leakage inductance of the coupled inductor, which usually generates voltage spikes during switching in many coupled-inductor based converters, plays an important role in providing ZCS to diodes $D_{1}$ and $D_{2}$ in the IBS-VM converter.
An accurate mathematical analysis considering the influence of the leakage inductance on the energy transfer process was detailed. Based on these results, the designer is able to determine the set of parameters that ensures the operation of the IBS-VM converter under pre-specified conditions. Moreover, the results could be used for an optimized converter design, since they provide the basis to compute all voltage and current stresses on the elements of the circuit. Experimental results validated the theoretical analysis and demonstrated the good performance of the IBSVM converter over a wide output power range.

Overall, the IBS-VM converter using a voltage multiplier cell has demonstrated potential for application in systems requiring a high-step-up dc-dc converter at power levels of hundreds of Watts, mainly due to its low input current ripple, high voltage gain with reduced duty cycle levels, high efficiency and need for only a single active switch.

\section{REFERENCES}

[1] U.S. Energy Information Administration, "International Energy Outlook", Sep. 2017.

[2] W. Li, X. He, "Review of Nonisolated High-Step-Up DC/DC Converters in Photovoltaic Grid-Connected Applications", in IEEE Transactions on Industrial Electronics, vol. 58, n. 4, pp. 1239-1250, April 2011.

[3] H. Liu, H. Hu, H. Wu, Y. Xing, I. Batarseh, "Overview of High-Step-Up Coupled-Inductor Boost Converters", in IEEE Journal of Emerging and Selected Topics in Power Electronics, vol. 04, $\mathrm{n}^{\mathrm{0}}$ 2, pp. 689-704, June 2016.

[4] M. Forouzesh, Y. P. Siwakoti, S. A. G. F. Blaabjerg, B. Lehman, "Step-Up DC-DC Converters: A Comprehensive Review of Voltage-Boosting Techniques, Topologies, and Applications", in IEEE Transactions on Power Electronics, vol. 32, $\mathrm{n}^{\mathrm{o}}$ 12, pp. 9143-9178, Dec. 2017.

[5] K. Park, G. Moon, M. Youn, "Nonisolated High Stepup Boost Converter Integrated With Sepic Converter", in IEEE Transactions on Power Electronics, vol. 25, no. 9, pp. 2266-2275, Sep. 2010.

[6] J. R. Dreher, A. M. S. S. Andrade, L. Schuch and M. L. S. Martins, "Coupled-Inductor High Step-Up Integrated Topologies: Synthesis, Analysis and Experimental Results", in Eletrônica de Potência-SOBRAEP, vol. 21, n 2, pp. 91-104, Mar./Jun. 2016.

[7] K. B. Park, G. W. Moon, M. J. Youn, "High Step-up Boost Converter Integrated with a TransformerAssisted Auxiliary Circuit Employing Quasi-Resonant Operation", in IEEE Transactions on Power Electronics, vol. 27, n 4, pp. 1974-1984, April 2012.

[8] S. W. Lee, H. L. Do, "Zero-Ripple Input-Current HighStep-Up Boost-SEPIC DC-DC Converter With Reduced Switch-Voltage Stress", in IEEE Transactions on Power Electronics, vol. 32, $\mathrm{n}^{\mathrm{o}}$ 8, pp. 6170-6177, Aug. 2017.

[9] S. W. Lee, H. L. Do, "Isolated SEPIC DC-DC Converter with Ripple-Free Input Current and Lossless Snubber", in IEEE Transactions on Industrial Electronics, vol. 65, n 2, pp. 1254-1262, Feb. 2018. 
[10] R. Gules, W. M. Santos, F. A. Reis, E. F. Ribeiro Romaneli, A. A. Badin, "A Modified SEPIC Converter With High Static Gain for Renewable Applications", in IEEE Transactions on Power Electronics, vol. 29, $\mathrm{n}^{\circ}$ 11, pp. 5860-5871, Nov. 2014.

[11] J. Yao, A. Abramovitz, K. M. Smedley, "Analysis and Design of Charge Pump-Assisted High Step-Up Tapped Inductor SEPIC Converter With an "Inductorless" Regenerative Snubber", in IEEE Transactions on Power Electronics, vol. 30, nº 10, pp. 5565-5580, Oct. 2015.

[12] R. Moradpour, H. Ardi, A. Tavakoli, "Design and Implementation of a New SEPIC-Based High Step-Up DC/DC Converter for Renewable Energy Applications", in IEEE Transactions on Industrial Electronics, vol. 65, n 2, pp. 1290-1297, Feb. 2018.

[13] H. Ardi, A. Ajami, "Study on A High Voltage Gain SEPIC Based DC-DC Converter with Continuous Input Current for Sustainable Energy Applications", in IEEE Transactions on Power Electronics, vol. 33, $\mathrm{n}^{\mathrm{0}}$ 12, pp. 10403-10409, Dec. 2018.

[14] S. Hasanpour, A. Baghramian, H. Mojallali, "A New High-Gain Coupled-Inductor SEPIC Converter for a Microgrid System", in Proc. of PEDSTC, pp. 294-299, 2017.

[15] A. M. S. S. Andrade, L. Schuch, H. L. Hey, M. L. S. Martins, "Conversor boost quadrático empilhado com o conversor zeta para aplicação de alto ganho de tensão", in Eletrônica de Potência-SOBRAEP, vol. 21, $\mathrm{n}^{\mathrm{o}}$ 4, pp. 274-284, Out./Dez. 2016.

[16] K. C. Tseng, T. J. Liang "Novel high-efficiency step-up converter", in IEE Proceedings - Electric Power Applications, vol. 151, n 2, pp. 182-190, Mar. 2004.

[17] A. M. S. S. Andrade, E. Mattos, L. Schuch, H. L. Hey, M. L. S. Martins, "Synthesis and Comparative Analysis of Very High Step-Up DC-DC Converters Adopting Coupled-Inductor and Voltage Multiplier Cells", in IEEE Transactions on Power Electronics, vol. 33, $\mathrm{n}^{\circ} 7$, pp. 5880-5897, Aug. 2018.

[18] J. W. Baek, M. H. Ryoo, T. J. Kim, D. W. Yoo, J. S. Kim, "High Boost Converter Using Voltage Multiplier," in Proc. of IECON, pp. 1-6, 2005.

[19] K. C. Tseng, C. C. Huang, W. Y. Shih, "A High StepUp Converter With a Voltage Multiplier Module for a Photovoltaic System", in IEEE Transactions on Power Electronics, vol. 28, nº 6, pp. 3047-3057, June 2013.

[20] G. V. T. Bascope; R. P. T. Bascope, D. S. Oliveira, “A Generalized High Voltage Gain Boost Converter Based on Three-State Switching Cell", in Proc. of IECON, pp. 1927-1932, 2006.

[21] C. Tseng, C. A. Cheng, C. T. Chen, "High Step-Up Interleaved Boost Converter for Distributed Generation Using Renewable and Alternative Power Sources", in IEEE Journal of Emerging and Selected Topics in Power Electronics, vol. 5, n⿳ 2, pp. 713-722, June 2017.

[22] L. F. Cosa; R. P. T. Bascopé; G. V. T. Bascopé; G. J. M. Sousa, R. G. A. Cacau, "A high voltage gain Sepic converter based on three-state switching cell", in Proc. of Induscon, pp. 1-6, 2010.

[23] Y. Zhao, W. Li, X. He, "Single-Phase Improved Active Clamp Coupled-Inductor-Based Converter With Extended Voltage Doubler Cell", in IEEE Transactions on Power Electronics, vol. 27, $\mathrm{n}^{\mathrm{o}}$ 8, pp. 2869-2878, June 2012.

[24] S. Sathyan, H. M. Suryawanshi, B. Singh, C. Chakraborty, V. Verma, M. S. Ballal, "ZVS-ZCS High Voltage Gain Integrated Boost Converter for DC Microgrid", in IEEE Transactions on Industrial Electronics., vol. 66, n ${ }^{\text {9 }}$, pp. 6898-6908, Nov. 2016.

[25] M. Forouzesh, Y. Shen, K. Yari, Y. P. Siwakoti, F. Blaabjerg, "High-Efficiency High Step-Up DC-DC Converter with Dual Coupled Inductors for GridConnected Photovoltaic Systems", in IEEE Transactions on Power Electronics, vol. 33, $\mathrm{n}^{\mathrm{0}}$ 7, pp. 5967-5982, July 2018.

[26] L. Schmitz, T. P. Horn, D. C. Martins, R. F. Coelho, "Conversor CC-CC de Alto Ganho Voltado para Aplicações Fotovoltaicas Com Módulos de Filme Fino", in Eletrônica de Potência-SOBRAEP, vol. 23, $n^{\circ} 3$, pp. 339-348, Jul./Set. 2018.

[27] V. Cardoso, T. B. Lazzarin, G. Waltrich, "Conversor duplo-boost-flyback de alto ganho", in Eletrônica de Potência -SOBRAEP, vol. 23, no 3, pp. 382-391, Jul./Set. 2018.

\section{BIOGRAPHIES}

Bruno Gomes de Assis, born in 05/26/1997 in Avaré-SP is an electrical engineering student with the Federal University of Technology - Parana. His areas of interest are: power converters and renewable energy processing.

Eduardo Pacheco Carreiro Braga, born in 10/20/1995 in Rio de Janeiro-RJ is an electrical engineering student with the Federal University of Technology - Parana. His areas of interest are: power converters, lighting systems, digital controllers and renewable energy processing.

Claudinor Bitencourt Nascimento, born in 06/05/1971 in Tubarão-SC is an electrical engineer (1994), master (1996) and doctor (2005) in Electrical Engineering with the Federal University of Santa Catarina. He is currently a titular professor at the Federal University of Technology - Parana. His areas of interest are: lighting system, power factor correction circuits and new converter topologies.

Eloi Agostini Júnior, born in $01 / 19 / 1983$ in Lages-SC is an electrical engineer (2006), master (2008) and doctor in Electrical Engineer (2012) with the Federal University of Santa Catarina. He is currently a full professor at the Federal University of Technology - Parana. His areas of interest are: power converters, soft switching, power factor correction, converter modeling and renewable energy processing. 